\title{
Pulmonary artery dilatation during normal pregnancy
}

\author{
Karolina Golińska-Grzybała ${ }^{1,2,3}$, Marcin Wiecheć ${ }^{3}$, Bogdan Goliński ${ }^{4}$, Paweł Rostoff ${ }^{1}$, \\ Anna Furman-Niedziejko' ${ }^{1}$, Andrzej Gackowski1 ${ }^{1,2}$, Jadwiga Nessler ${ }^{1}$, Grzegorz Gajos ${ }^{1}$, Ewa Konduracka ${ }^{1}$ \\ 'Department of Coronary Disease and Heart Failure, Jagiellonian University Medical College, John Paul II Hospital, Krakow, Poland \\ ${ }^{2}$ Noninvasive Cardiovascular Laboratory, John Paul II Hospital, Krakow, Poland \\ ${ }^{3}$ Department of Gynaecology and Obstetrics, University Hospital, Krakow, Poland \\ ${ }^{4}$ Multimed Medical Centre, Outpatient Clinic, Brzesko, Poland
}

\begin{abstract}
Background: During pregnancy the cardiovascular system undergoes complex alterations; however, there have been few studies concerning pulmonary artery behaviour during gestation.

Aim: The aim of this study was to evaluate changes in the pulmonary artery diameter (PAD) during gestation, with respect to left ventricular (LV) load and remodelling, as well as to systemic vascular resistance (SVR).

Methods: It was a prospective cohort study, which included 69 consecutive healthy outpatient women with a singleton pregnancy. Echocardiography and ultrasonography of the uterine arteries were performed at two visits (V1 and V2) during pregnancy, and only echocardiography at one visit postpartum.

Results: Pulmonary artery diameter increased in all women, from $20.0 \mathrm{~mm}$ at $\mathrm{V} 1$ to $22.7 \mathrm{~mm}$ at V2 ( $\mathrm{p}<0.001$ ), and it returned to the reference range postpartum $(19.5 \mathrm{~mm} ; \mathrm{p}<0.001 \mathrm{vs}$. V2). Echocardiography did not reveal any other abnormalities, including the signs of intracardiac shunt or right ventricular pressure overload. During V2, PAD positively correlated with the following echocardiographic parameters: LV end-diastolic diameter $(r=0.386 ; p=0.002)$, LV end-systolic diameter $(r=0.345 p=0.006)$, LV end-diastolic volume $(r=0.308 ; p=0.016)$, LV mass $(r=0.459 ; p<0.001)$, left atrial area $(r=0.334 ; p=0.009)$, LV cardiac output $(r=0.338 ; p=0.011)$, and aortic diameter $(r=0.369 ; p=0.003)$. Furthermore, there was a negative linear correlation between PAD and SVR $(r=-0.307 ; p=0.025)$ and pulsatility index $(r=-0.318 ; p=0.012)$.

Conclusions: Our study shows pulmonary artery dilatation in healthy pregnant women without any other abnormal echocardiographic findings. These changes in PAD are associated with volume overload and low vascular resistance, and during postpartum they usually subside.
\end{abstract}

Key words: pulmonary artery diameter, pregnancy, uterine artery, pulsatility index

Kardiol Pol 2018; 76, 11: 1542-1550

\section{INTRODUCTION}

A proper adaptation of the cardiovascular system during pregnancy is essential to cover higher metabolic demand of both the mother and the foetus and to provide sufficient uteroplacental circulation. Pregnancy is characterised as a high-volume, low-resistance state [1], during which systemic vasodilation occurs at five weeks after conception and reaches the nadir in the middle of the second trimester (decreasing by 35\% to $40 \%$ of the baseline value) [1]. The plasma volume starts to increase at between six to eight weeks and continues to rise until 28 to
30 weeks of gestation. The increase is mediated by complex changes in the endocrine system that lead to hyponatraemic hypervolaemia [2]. These changes in blood volume cause heart adaptation in terms of a mild four-chamber dilatation and a progressive increase in cardiac output due to an early increase in stroke volume and subsequent increase in heart rate [2, 3]. What is more, aortic distensibility is increased during normal pregnancy and manifests as a mild increment in aortic diameter during the second trimester in comparison with non-pregnant women. The mechanism by which the aortic stiffness decreases

\section{Address for correspondence:}

Ewa Konduracka, MD, PhD, Department of Coronary Disease and Heart Failure, Jagiellonian University Medical College, John Paul II Hospital, ul. Prądnicka 80 , 31-202 Kraków, Poland, tel: +48 501520 617, fax: +48 1243343 76, e-mail: ekonduracka@interia.eu

Received: 25.04.2018 Accepted: 23.07.2018 Available as AoP: 24.07.2018

Kardiologia Polska Copyright (C) Polish Cardiac Society 2018 
is unrelated to mechanical stress and is probably the result of intrinsic changes in the aortic wall, mediated by high blood levels of oestrogen $[4,5]$.

Data concerning the adaptation of the pulmonary artery to healthy pregnancy are scarce. Therefore, the aim of this study was to evaluate changes in the pulmonary artery diameter (PAD) and their correlations with cardiac remodelling and haemodynamic parameters throughout gestation.

\section{METHODS}

\section{Study population}

Our research was designed as a prospective cohort study. A total of 86 consecutive healthy outpatients with a single pregnancy confirmed during an obstetric visit were enrolled in the study between 2014 and 2015 in Brzesko, Poland. The exclusion criteria were as follows: 1) any cardiovascular and pulmonary disorders that could contribute to pulmonary artery dilatation, which were diagnosed before or during pregnancy, including hypertension, venous thromboembolism, cardiac surgery, or chronic pulmonary diseases (e.g. asthma, sarcoidosis), and 2) gestosis in previous and present pregnancies. Women were also asked to present all blood test results performed during pregnancy.

Three visits were scheduled during the study:

- baseline visit (V1) at the end of the first trimester (between weeks 10 and 14);

- second visit (V2) between the second and third trimesters (between weeks 25 and 30);

- follow-up visit (V3) postpartum (between weeks 12 and 38).

The time of the visits during pregnancy was chosen to show changes in blood flow in uterine arteries.

All participants gave their written informed consent to participate in the study. The study was approved by the Local Ethics Committee, and the study protocol complied with the Declaration of Helsinki.

\section{Clinical examinations}

History taking and physical examination were performed during all three visits. Among others, blood pressure and weight were measured, and body mass index was calculated (as weight in kilograms divided by the square of height in metres). Blood pressure was measured before echocardiography, after five-minute rest in a sitting position, from the right arm, and using an aneroid sphygmomanometer.

\section{Echocardiography}

Full echocardiographic procedures were performed at $\mathrm{V} 1$ and V2 in all participants. During V3 mainly the pulmonary artery dimension and pulmonary-to-systemic flow (Qp/Qs) ratio were assessed.

Women were examined in a left decubitus position, using a Vivid S5 ultrasound (GE, Solingen, Germany) equipped with the multi-frequency harmonic transducer 3Sc-RS
(1.3-4 MHz). All measurements were carried out according to joint recommendations of the American Society of Echocardiography and European Association of Echocardiography $[6,7]$. The right ventricular (RV) diameter was obtained from the basal one-third of the RV after adjustment from an apical four-chamber view to an RV-focused view. RV outflow tract diameter (RVOT-proximal) was assessed from a parasternal long-axis view (PLAX) at the end-diastolic phase.

To calculate the Qp/QS ratio, RVOT-distal diameter was measured from a parasternal short-axis view, proximal to the pulmonary valve. From the same window, the PAD at the end-diastolic phase was also measured, approximately $1 \mathrm{~cm}$ below the pulmonary valve, using the leading-edge method.

A PAD of $21 \mathrm{~mm}$ or less was considered to be within the reference range [7]. RV systolic pressure (RVSP) was determined from the peak tricuspid regurgitation jet velocity $(\mathrm{V})$ and right atrial (RA) pressure (RVSP $=4[\mathrm{~V}]^{2}+\mathrm{RA}$ pressure). RA pressure was derived from the changes in the diameter of the inferior vena cava during respiration [7].

From the PLAX view in two-dimensional images, the left ventricular (LV) end-diastolic diameter (LVEDD) and LV end-systolic diameter (LVESD), interventricular septum diameter (IVSD), and posterior wall diameter (PWD) at the end-diastolic phase, as well as LV outflow tract at the mid-systolic phase, were measured. From the same view, after obtaining the best visualisation of the ascending aorta, the maximum aortic diameter at the end-diastolic phase was also measured. The areas of the right and left atria were planimetered in the apical four-chamber view. LV mass was calculated using the following equation: $0.8 \times\left(1.04 \times\left[(\text { LVEDD }+ \text { PWD + IVSD })^{3}-(\text { LVEDD })^{3}\right]+0.6\right)$, and then indexed to body surface area. Relative wall thickness (RWT) was calculated using the following formula: RWT $=2 \times$ PWD/LVEDD. LV end-diastolic (LVEDV) and end-systolic (LVESV) volumes, stroke volume, and ejection fraction were calculated using the biplane Simpson method. The LV cardiac output (LVCO) was calculated as the product between LV stroke volume and heart rate. Systemic vascular resistance (SVR) was estimated using the following formula: $80 \times$ mean arterial pressure/LVCO $\left(\right.$ dyn $\left.\cdot s \cdot \mathrm{cm}^{-5}\right)$, whereas mean arterial pressure was calculated using the following equation: systolic blood pressure $+(2 \times$ diastolic blood pressure)/3. Pulmonary artery acceleration time (ACT) was measured by sampling the RV outflow with pulsed-wave Doppler ultrasound.

\section{Assessment of blood flow in uterine arteries}

Women were examined in a supine position, and both arteries were visualised using a 4C RS (1.8-6.0 MHz) transducer (Vivid S5 ultrasound; GE). Blood flow was assessed by colour and pulsed-wave Doppler ultrasound. Before the measurements, the probe position was adjusted so that the artery angle was $60^{\circ}$ or less. The pulsatility index $(\mathrm{PI})$ was calculated by the following equation: (peak systolic velocity - end-diastolic 
velocity) / time-averaged velocity. The resistive index was estimated using the following formula: (peak systolic velocity - end-diastolic velocity) / peak systolic velocity. All measurements were performed according to the applicable guidelines $[8,9]$. The average values of three consecutive measurements were recorded.

\section{Intra-observer and inter-observer agreement}

To calculate an intra-observer agreement for two-dimensional and Doppler ultrasound measurements, a re-analysis of 10 randomly selected women was performed by a first investigator (blinded to the initial results) at least four weeks after the first examination. To assess the inter-observer agreement, the same data sets were analysed by a second observer (A.F.N.). The agreement between the two measurements was presented using the $95 \%$ confidence interval $(\mathrm{Cl})$ determined as the mean of the differences \pm 1.96 standard deviation (SD).

\section{Statistical analysis}

Categorical variables were expressed as a proportion of the overall study population, and the differences were compared using the $\chi^{2}$ or Fisher's exact test. Continuous variables were presented as mean $\pm \mathrm{SD}$, and the Mann-Whitney $U$ test was used for the comparison. The changes in PAD over time were assessed using the analysis of variance for repeated measurements and Bonferroni post hoc correction for multiple comparisons.

We calculated the sample size sufficient to show aorta augmentation, assuming that the PAD would also significantly increase in this study group. A sample size of 11 women would be required to detect an increase of $2 \mathrm{~mm}$ in the aorta diameter during pregnancy (between the first and third trimesters) at a p-value of less than 0.05 and a power of $90 \%$. We recruited a sample that was twice this size to allow for patient dropout.

Correlations between the PAD and echocardiographic parameters were analysed using Pearson correlation. Differences with a p-value of less than 0.05 were considered significant. A stepwise logistic regression analysis was performed to determine the independent predictors of pulmonary artery dilatation during normal pregnancy in the study population. The calibration and discrimination of the developed model were assessed using the Hosmer-Lemeshow test and area under the receiver operating characteristic curve analysis, respectively. For the analysis, pulmonary artery dilatation was defined as a PAD exceeding $21 \mathrm{~mm}$.

The statistical analysis was performed using Statistica software, version 13.1 (Dell Software Int. Ltd., City Gate Park, Mahon, Cork, Ireland).

\section{RESULTS}

Out of 86 women enrolled at baseline, 17 were excluded from the study (13 missed the second or follow-up visit, and four were diagnosed with pregnancy-induced hypertension).

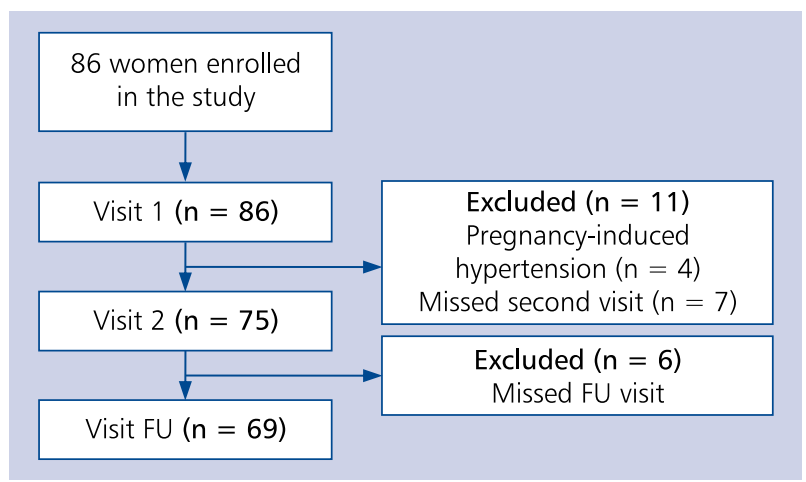

Figure 1. Flowchart of the study population; FU — follow-up

In total, 69 women were included in the analysis (Fig. 1). At baseline, the mean age of all participants was $29.5 \pm 4.7$ years (range, 19.8-42.3 years). On admission to the study, for 29 (42\%) women, it was the first pregnancy; for 21 (30.5\%), the second; and for 19 (27.5\%), the third or subsequent pregnancy. The course of gestation and labour was normal in all women and none of them suffered from dyspnoea. Demographic and echocardiographic findings for all studied women are presented in Table 1.

\section{Pulmonary artery diameter}

The PAD increased in the overall study population, from $20.0 \mathrm{~mm}$ at $\mathrm{V} 1$ to $22.5 \mathrm{~mm}$ at $\mathrm{V} 2$, and it returned to normal values postpartum (19.5 mm; p < 0.001 vs. V2) (Fig. 2, Table 2). For statistical analysis, patients were classified into a group with pulmonary artery dilatation $(\mathrm{PAD}>21 \mathrm{~mm}$ at any visit; group A) and a group with normal pulmonary artery dimension at both visits (group B). There were no differences between groups A and B with respect to age (29.1 vs. 29.6; $p=0.693$ ), number of current pregnancy (2.3 vs. $1.8 ; p=0.745)$, and prevalence of smoking before pregnancy (13\% vs. 11\%; $\mathrm{p}=0.824)$. Furthermore, we did not observe significant differences in body mass index and weight at visits V1 and V2 in the study subgroups.

The average mean increase in PAD between $\mathrm{V} 1$ and V2 was $20 \%$ in group $A$ and $9 \%$ in group $B(p<0.001$; Table 2$)$. In group $A$, during $\mathrm{V} 2$, mild pulmonary artery dilatation (PAD < $26 \mathrm{~mm}$ ) was detected in 17 (74\%) women; moderate (26-29 mm), in four (17\%); and severe (> $30 \mathrm{~mm})$, in two (9\%). The maximum increase in PAD was $10 \mathrm{~mm}$ in one participant. A detailed echocardiographic assessment did not reveal other abnormalities, including signs of intracardiac shunt (the Qp/Qs ratio was within the reference range in all women at each visit) or RV pressure overload (the maximum value of RVSP in the overall population was $20 \mathrm{mmHg}$ ). The postpartum visit showed normalisation of PAD among women in both study subgroups. Nevertheless, in group A, it was still augmented in comparison with group B (20.5 mm vs. 18.9 mm, respectively, 
Table 1. Demographic and echocardiographic data of all studied women $(\mathrm{n}=69)$

\begin{tabular}{|c|c|c|c|}
\hline & Visit 1 (10-14 week) & Visit 2 (25-30 week) & p \\
\hline Body weight $[\mathrm{kg}]$ & $67 \pm 13$ & $75 \pm 12$ & $<0.001$ \\
\hline $\mathrm{BMI}\left[\mathrm{kg} / \mathrm{m}^{2}\right]$ & $25 \pm 6$ & $27 \pm 7$ & $<0.001$ \\
\hline Heart rate $[\mathrm{bpm}]$ & $78 \pm 9$ & $82 \pm 9$ & $<0.001$ \\
\hline Systolic BP [mmHg] & $118 \pm 18$ & $116 \pm 11$ & 0.515 \\
\hline Diastolic BP [mmHg] & $77 \pm 9$ & $74 \pm 10$ & 0.007 \\
\hline $\mathrm{MAP}[\mathrm{mmHg}]$ & $91 \pm 9$ & $88 \pm 9$ & 0.031 \\
\hline \multicolumn{4}{|c|}{ Echocardiographic parameters: } \\
\hline LVEF [\%] & $65 \pm 5$ & $64 \pm 4$ & 0.153 \\
\hline LVEDD $[\mathrm{mm}]$ & $45 \pm 4$ & $47 \pm 4$ & 0.004 \\
\hline LVESD $[\mathrm{mm}]$ & $29 \pm 4$ & $31 \pm 4$ & 0.002 \\
\hline LVEDV [mL] & $89 \pm 13$ & $97 \pm 15$ & $<0.001$ \\
\hline LVESV [mL] & $53 \pm 18$ & $61 \pm 10$ & $<0.001$ \\
\hline LV mass [g] & $104 \pm 22$ & $118 \pm 20$ & $<0.001$ \\
\hline LV mass index $\left[\mathrm{g} / \mathrm{m}^{2}\right]$ & $59 \pm 11$ & $65 \pm 9$ & $<0.001$ \\
\hline SVR $\left[\right.$ dyn $\left.\cdot S \cdot \mathrm{cm}^{-5}\right]$ & $1658 \pm 329$ & $1415 \pm 307$ & $<0.001$ \\
\hline LVCO [L/min] & $4 \pm 0.9$ & $5 \pm 1$ & 0.002 \\
\hline RWT & $0.33 \pm 0.07$ & $0.36 \pm 0.05$ & 0.020 \\
\hline LA area $\left[\mathrm{cm}^{2}\right]$ & $17 \pm 2$ & $19 \pm 2$ & $<0.001$ \\
\hline LAV index $\left[\mathrm{mL} / \mathrm{m}^{2}\right]$ & $28 \pm 5$ & $31 \pm 6$ & $<0.001$ \\
\hline $\mathrm{RA}$ area $\left[\mathrm{cm}^{2}\right]$ & $15 \pm 2$ & $15 \pm 3$ & 0.411 \\
\hline RVOT prox. [mm] & $27 \pm 3$ & $27 \pm 3$ & 0.793 \\
\hline $\mathrm{RVD}[\mathrm{mm}]$ & $35 \pm 3$ & $36 \pm 3$ & 0.086 \\
\hline ACT [ms] & $120 \pm 12$ & $117 \pm 14$ & 0.373 \\
\hline TAPSE [mm] & $26 \pm 3$ & $26 \pm 4$ & 0.588 \\
\hline Aorta [mm] & $26 \pm 3$ & $27 \pm 2$ & 0.017 \\
\hline
\end{tabular}

Data are presented as mean \pm standard deviation. ACT — acceleration time; BMI — body mass index; BP — blood pressure; LA — left atrium; LAV — left atrial volume; LV — left ventricular; LVCO — left ventricular cardiac output; LVEDD — left ventricular end-diastolic diameter; LVEDV — left ventricular end-diastolic volume; LVEF — left ventricular ejection fraction; LVESD — left ventricular end-systolic diameter; MAP — mean arterial pressure; RA — right atrium; RVD — right ventricular diameter; RVOT — right ventricular outflow tract; RWT — relative wall thickness; SVR — systemic vascular resistance; TAPSE — tricuspid annular plane systolic excursion

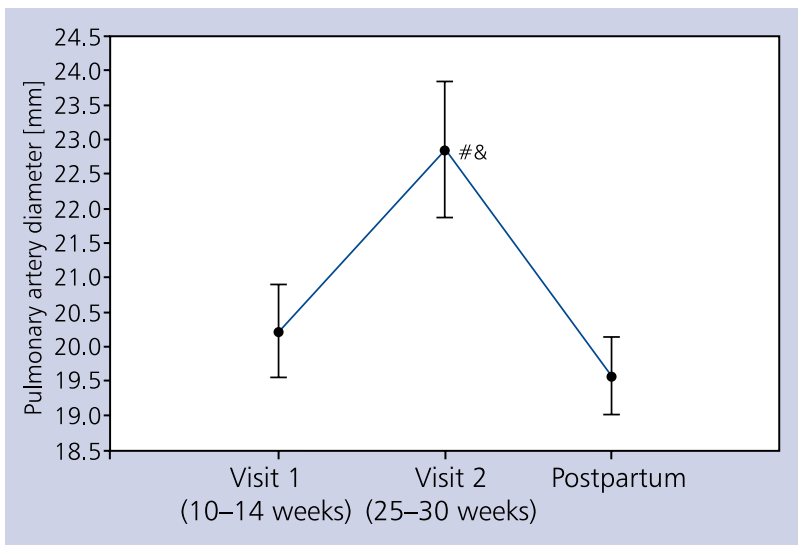

Figure 2. Changes in pulmonary artery diameter during pregnancy and postpartum in the overall group $(n=69)$. Data are presented as mean \pm standard deviation; ${ }^{*} p<0.05$ vs. visit $1 ;{ }^{\&} p<0.05$ vs. postpartum $p=0.002$ ). The comparison of other haemodynamic, echocardiographic, and uterine artery Doppler parameters in the study subgroups is presented in Tables 3, 4, and 5.

\section{Predictors of pulmonary artery dilatation}

The results of a univariate logistic regression analysis of pulmonary artery dilatation during normal pregnancy are shown in Table 6. A multivariate logistic regression analysis showed that the RA area and LVESD measured at V2 were the only independent predictors of pulmonary artery dilatation (odds ratio [OR] 1.67; 95\% $\mathrm{Cl} 1.01-2.77 ; \mathrm{p}=0.047$ and OR 1.51; 95\% Cl 1.08-2.10; $p=0.016$, respectively).

\section{Haemodynamic correlations observed during 25-30 weeks of gestation}

In the overall study population, PAD positively correlated with the following echocardiographic parameters: LVEDD 
Table 2. Changes in pulmonary artery diameter (PAD) in the study population and in the study groups ( $A$ and $B$ )

\begin{tabular}{|c|c|c|c|c|}
\hline & $\begin{array}{c}\text { Visit } 1 \\
\text { (10-14 week) }\end{array}$ & $\begin{array}{c}\text { Visit } 2 \\
\text { (25-30 week) }\end{array}$ & $\begin{array}{l}\text { Postpartum } \\
\text { (12-38 week) }\end{array}$ & $\mathbf{p}$ \\
\hline $\operatorname{PAD}(\mathrm{n}=69)[\mathrm{mm}]$ & $20 \pm 0.3$ & $22 \pm 0.4 \#^{*}$ & $19 \pm 0.2$ & $<0.001$ \\
\hline Group A $(\mathrm{n}=23)[\mathrm{mm}]$ & $21 \pm 0.7$ & $25 \pm 0.8 \#^{*}$ & $20 \pm 0.6$ & $<0.001$ \\
\hline Group B $(\mathrm{n}=46)[\mathrm{mm}]$ & $19 \pm 0.3$ & $21 \pm 0.2 \#^{*}$ & $19 \pm 0.2$ & $<0.001$ \\
\hline
\end{tabular}

Data are presented as mean \pm standard deviation. P-values derived from ANOVA for repeated measurements.

$\# p<0.05$ vs. visit 1 using Bonferroni post hoc correction for repeated measurements

${ }^{*} \mathrm{p}<0.05$ vs. postpartum using Bonferroni post hoc correction for repeated measurements.

Table 3. Haemodynamic data in the study groups

\begin{tabular}{|c|c|c|c|}
\hline & $\begin{array}{c}\text { Group A }(n=23) \\
\text { Mean PAD }>21 \mathrm{~mm}\end{array}$ & $\begin{array}{c}\text { Group B }(n=46) \\
\text { Mean PAD } \leq 21 \mathrm{~mm}\end{array}$ & $\mathbf{p}$ \\
\hline \multicolumn{4}{|c|}{ Parameters at visit 1 (10-14 weeks): } \\
\hline Heart rate [bmp] & $77 \pm 10$ & $78 \pm 9$ & 0.283 \\
\hline Systolic BP [mmHg] & $121 \pm 11$ & $116 \pm 19$ & 0.283 \\
\hline Diastolic BP [mmHg] & $75 \pm 10$ & $77 \pm 8$ & 0.471 \\
\hline $\mathrm{MAP}[\mathrm{mmHg}]$ & $91 \pm 11$ & $90 \pm 9$ & 0.983 \\
\hline SVR $\left[\right.$ dyn $\left.\cdot s \cdot \mathrm{cm}^{-5}\right]$ & $1653 \pm 353$ & $1599 \pm 331$ & 0.585 \\
\hline LVCO $[\mathrm{L} / \mathrm{min}]$ & $4 \pm 0.8$ & $5 \pm 0.9$ & 0.322 \\
\hline \multicolumn{4}{|c|}{ Parameters at visit 2 (25-30 weeks): } \\
\hline Heart rate $[\mathrm{bpm}]$ & $85 \pm 11^{*}$ & $88 \pm 9 * *$ & 0.205 \\
\hline Systolic BP [mmHg] & $115 \pm 13$ & $117 \pm 11$ & 0.515 \\
\hline Diastolic BP [mmHg] & $74 \pm 11$ & $74 \pm 9^{*}$ & 0.968 \\
\hline $\mathrm{MAP}[\mathrm{mmHg}]$ & $87 \pm 11$ & $88 \pm 9^{*}$ & 0.778 \\
\hline SVR $\left[\right.$ dyn $\left.\cdot s \cdot \mathrm{cm}^{-5}\right]$ & $1270 \pm 167^{* *}$ & $1460 \pm 362$ & 0.044 \\
\hline LVCO [L/min] & $6 \pm 1^{* *}$ & $4 \pm 1^{\#}$ & 0.002 \\
\hline
\end{tabular}

Data are presented as mean \pm standard deviation. Abbreviations - see Table $1 .{ }^{*} \mathrm{p}<0.05$ compared with visit $1 ;{ }^{* *} \mathrm{p}<0.005$ compared with visit $1 ; \# p<0.00001$ compared with visit 1

$(r=0.411 ; p=0.003), \operatorname{LVESD}(r=0.345 ; p=0.006)$, LVEDV $(r=0.308 ; p=0.016)$, left atrial area $(r=0.334 ; p=0.009)$, $\operatorname{LVCO}(r=0.338 ; p=0.011)$, and aortic diameter $(r=0.399$; $p=0.004)$. Moreover, there was a negative linear relationship between PAD and SVR ( $r=-0.307 ; p=0.025)$ and PI $(r=-0.307 ; p=0.007$; Fig. 3$)$.

\section{Measurement variability}

The inter-observer agreement for echocardiographic measurements (mean $\pm 1.96 \mathrm{SD}$ ) was: $0.3 \pm 2.4 \mathrm{~mm}$ for PAD at $\mathrm{V} 1$, $-0.5 \pm 2.2 \mathrm{~mm}$ for PAD at $\mathrm{V} 2$, and $0.4 \pm 1.7 \mathrm{~mm}$ for PAD at postpartum visit, whereas the intra-observer variability for the same parameters was equal to $0.8 \pm 2.4 \mathrm{~mm}, 0.7 \pm 2.9 \mathrm{~mm}$, and $-0.6 \pm 1.9 \mathrm{~mm}$, respectively. For LV measurements the inter-observer agreement was $0.6 \pm 3.1 \mathrm{~mm}$ for LV diameters, $0.01 \pm 1.4 \mathrm{~mm}$ for wall thickness, $1.4 \pm 15 \mathrm{ml}$ for LVEDV, and $0.9 \pm 12 \mathrm{~mL}$ for LVESV.
The intra-observer variability showed values of $0.8 \pm 3.5 \mathrm{~mm},-0.01 \pm 1.8 \mathrm{~mm}, 2.5 \pm 16 \mathrm{~mL}$, and $-1.5 \pm 12 \mathrm{~mL}$, respectively.

\section{DISCUSSION}

Most of the haemodynamic changes and subsequent cardiac remodelling observed in all women in our study are characteristic of normal pregnancy and are consistent with findings from other studies [1, 2, 10-14]. This applies to an increase in heart rate, LV stroke volume, and LVCO, and to a decrease in SVR. Our results are comparable with those of other studies, although the absolute values of stroke volume were smaller in comparison with those reported in other studies $[2,11$, $12,15]$. For example, in a study by Savu et al. [2] stroke volume was higher than that in our study, while LVCO was similar. These discrepancies may have resulted from the differences in methodology. To assess stroke volume Savu et 
Table 4. Echocardiographic characteristics of the study groups

\begin{tabular}{|c|c|c|c|}
\hline & $\begin{array}{c}\text { Group A }(n=23) \\
\text { Mean PAD > } 21 \mathrm{~mm}\end{array}$ & $\begin{array}{c}\text { Group B }(n=46) \\
\text { Mean PAD } \leq 21 \mathrm{~mm}\end{array}$ & $\mathbf{p}$ \\
\hline \multicolumn{4}{|c|}{ Parameters at visit 1 (10-14 weeks): } \\
\hline LVEF [\%] & $64 \pm 5$ & $65 \pm 6$ & 0.433 \\
\hline LVEDD $[\mathrm{mm}]$ & $46 \pm 4$ & $45 \pm 4$ & 0.680 \\
\hline LVESD $[\mathrm{mm}]$ & $30 \pm 4$ & $29 \pm 4$ & 0.608 \\
\hline LVEDV $[\mathrm{mL}]$ & $90 \pm 13$ & $89 \pm 14$ & 0.813 \\
\hline LVSV [mL] & $58 \pm 9$ & $59 \pm 10$ & 0.751 \\
\hline LV mass [g] & $112 \pm 24$ & $99 \pm 20$ & 0.023 \\
\hline LV mass index $\left[\mathrm{g} / \mathrm{m}^{2}\right]$ & $64 \pm 13$ & $57 \pm 8$ & 0.022 \\
\hline LV mass $/ \mathrm{h}^{2.7}\left[\mathrm{~g} / \mathrm{m}^{2.7}\right]$ & $28 \pm 6$ & $26 \pm 6$ & 0.102 \\
\hline RWT & $0.34 \pm 0.1$ & $0.34 \pm 0.05$ & 0.991 \\
\hline LA area $\left[\mathrm{cm}^{2}\right]$ & $18 \pm 2$ & $17 \pm 2$ & 0.270 \\
\hline$L A V$ index $\left[\mathrm{mL} / \mathrm{m}^{2}\right]$ & $29 \pm 5$ & $28 \pm 4$ & 0.390 \\
\hline RA area $\left[\mathrm{cm}^{2}\right]$ & $15 \pm 2$ & $15 \pm 2$ & 0.088 \\
\hline RVOT prox. $[\mathrm{mm}]$ & $26 \pm 3$ & $27 \pm 3$ & 0.691 \\
\hline $\mathrm{RVD}[\mathrm{mm}]$ & $35 \pm 3$ & $35 \pm 2$ & 0.625 \\
\hline $\mathrm{ACT}[\mathrm{ms}]$ & $119 \pm 11$ & $121 \pm 12$ & 0.516 \\
\hline TAPSE $[\mathrm{mm}]$ & $27 \pm 3$ & $26 \pm 3$ & 0.459 \\
\hline $\mathrm{RVSP}[\mathrm{mmHg}]$ & $16 \pm 2$ & $12 \pm 5$ & 0.746 \\
\hline Aorta $[\mathrm{mm}]$ & $27 \pm 3$ & $26 \pm 3$ & 0.175 \\
\hline \multicolumn{4}{|c|}{ Parameters at visit 2 (25-30 weeks): } \\
\hline LVEF [\%] & $63 \pm 3$ & $63 \pm 4$ & 0.443 \\
\hline LVEDD $[\mathrm{mm}]$ & $48 \pm 3^{*}$ & $46 \pm 3$ & 0.019 \\
\hline LVESD $[\mathrm{mm}]$ & $33 \pm 5^{* *}$ & $29 \pm 3^{*}$ & 0.001 \\
\hline LVEDV $[\mathrm{mL}]$ & $103 \pm 14^{* *}$ & $93 \pm 15$ & 0.024 \\
\hline LVSV [mL] & $65 \pm 9^{*}$ & $59 \pm 9$ & 0.025 \\
\hline LV mass $[\mathrm{g}]$ & $128 \pm 17^{* *}$ & $113 \pm 19^{\#}$ & 0.005 \\
\hline LV mass index $\left[\mathrm{g} / \mathrm{m}^{2}\right]$ & $69 \pm 9^{*}$ & $62 \pm 8^{* *}$ & 0.012 \\
\hline LV mass $/ \mathrm{h}^{2.7}\left[\mathrm{~g} / \mathrm{m}^{2.7}\right]$ & $33 \pm 4^{* *}$ & $29 \pm 6^{* * *}$ & 0.058 \\
\hline RWT & $0.36 \pm 0.05$ & $0.37 \pm 0.04$ & 0.762 \\
\hline LA area $\left[\mathrm{cm}^{2}\right]$ & $19 \pm 2^{*}$ & $18 \pm 2^{* *}$ & 0.412 \\
\hline LAV index $\left[\mathrm{mL} / \mathrm{m}^{2}\right]$ & $32 \pm 7^{*}$ & $31 \pm 5^{* *}$ & 0.704 \\
\hline RA area $\left[\mathrm{cm}^{2}\right]$ & $16 \pm 2^{*}$ & $15 \pm 3$ & 0.087 \\
\hline RVOT prox. [mm] & $26 \pm 3$ & $27 \pm 3$ & 0.196 \\
\hline $\mathrm{RVD}[\mathrm{mm}]$ & $36 \pm 3$ & $36 \pm 3$ & 0.754 \\
\hline $\mathrm{ACT}[\mathrm{ms}]$ & $120 \pm 16$ & $118 \pm 14$ & 0.804 \\
\hline TAPSE $[\mathrm{mm}]$ & $26 \pm 3$ & $27 \pm 4$ & 0.318 \\
\hline $\mathrm{RVSP}[\mathrm{mmHg}]$ & $15 \pm 3$ & $18 \pm 4$ & 0.171 \\
\hline Aorta [mm] & $28 \pm 3$ & $26 \pm 2$ & 0.005 \\
\hline
\end{tabular}

Data are presented as mean \pm standard deviation. LVSV — left ventricular stroke volume; RVSP — right ventricular systolic pressure; other abbreviations - see Table 1. ${ }^{*} p<0.05$ compared with visit $1 ;{ }^{* *} p<0.005$ compared with visit $1 ;{ }^{* * *} p<0.0001$ compared with visit 1 ; $\# \mathrm{p}<0.00001$ compared with visit 1

al. [2] used the Doppler technique, while we used the biplane Simpson method for the calculation. Surprisingly, unlike other studies, which reported both RA and RV enlargement
$[1,14,15]$, we observed only mild RA dilatation in group A (Table 4). The reason why we did not observe RV enlargement remains unclear and requires further examination. The 
Table 5. Assessment of blood flow in uterine arteries in the study groups

\begin{tabular}{|c|c|c|c|}
\hline & $\begin{array}{c}\text { Group A }(n=23) \\
\text { PAD }>21 \mathrm{~mm}\end{array}$ & $\begin{array}{c}\text { Group B }(n=46) \\
P A D \leq 21 \mathrm{~mm}\end{array}$ & p \\
\hline \multicolumn{4}{|c|}{ Parameters at visit 1 (10-14 week): } \\
\hline $\mathrm{Pl}$ & $1.3 \pm 0.6$ & $1.5 \pm 0.5$ & 0.244 \\
\hline $\mathrm{RI}$ & $0.6 \pm 0.2$ & $0.7 \pm 0.1$ & 0.234 \\
\hline \multicolumn{4}{|c|}{ Parameters at visit 2 (25-30 week): } \\
\hline $\mathrm{Pl}$ & $0.5 \pm 0.1$ & $0.7 \pm 0.2$ & 0.103 \\
\hline $\mathrm{RI}$ & $0.4 \pm 0.1$ & $0.4 \pm 0.1$ & 0.278 \\
\hline
\end{tabular}

Data are presented as mean \pm standard deviation. PAD — pulmonary artery diameter; $\mathrm{PI}$ — pulsatility index; $\mathrm{RI}$ — resistive index

Table 6. Univariate logistic regression analysis of pulmonary artery dilatation during normal pregnancy

\begin{tabular}{|lcc|}
\hline \multirow{2}{*}{ Variable } & \multicolumn{2}{c}{ Univariate analysis } \\
\cline { 2 - 3 } & OR $(95 \% \mathrm{CI})$ & $\mathbf{p}$ \\
\hline PAD V1 & $2.46(1.45-4.17)$ & $<0.001$ \\
Aorta V1 & $1.52(1.05-2.18)$ & 0.007 \\
LV mass V1 & $1.04(1.01-1.07)$ & 0.017 \\
LVEDD V2 & $1.28(1.04-1.58)$ & 0.009 \\
LVESD V2 & $1.24(1.02-1.51)$ & 0.021 \\
LVSV V2 & $1.07(1.00-1.16)$ & 0.036 \\
RA area V2 & $1.55(1.10-2.12)$ & 0.002 \\
LV mass V2 & $1.07(1.02-1.21)$ & $<0.001$ \\
Aorta V2 & $1.76(1.12-2.77)$ & 0.004 \\
\hline
\end{tabular}

$\mathrm{Cl}$ - confidence interval; OR - odds ratio; $\mathrm{V} 1$ - visit 1 ; V2 - visit 2; other abbreviations - see tables 1, 4, 5

possible explanation of these discrepancies may result from the difference in the schedule of visits (especially V1 and V2) in our study in comparison with those reported in other studies. Other investigators, who planned three or four visits during pregnancy, observed RA dilatation between the first and third trimesters (after 34 gestational weeks), when the increase in plasma volume is the highest $[14,15]$. Moreover, Melchiorre et al. [14] reported that tricuspid annular plane systolic excursion (TAPSE) declined significantly near term and returned to normal values postpartum, whereas in a study by Ducas et al. [15], the TAPSE values between the first and third trimesters were stable, which is in line with our results.

To the best of our knowledge, we were the first to show that during pregnancy the PAD may increase by 1 to $10 \mathrm{~mm}$ (average $2 \mathrm{~mm}$ ), especially between the second and third trimesters in comparison with the first trimester, and it may return to the reference values postpartum. These morphological changes of the pulmonary artery in our study had no influence on the course of any pregnancies and labour. There are a few possible explanations for this phenomenon.

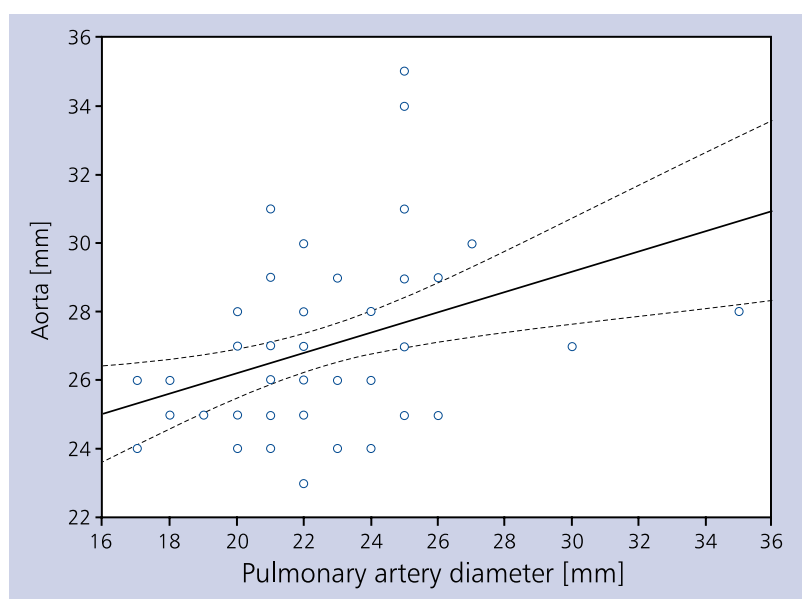

Figure 3. Correlation between pulmonary artery diameter and aorta at visit $2(p<0.05 ; r=0.399)$

One possibility is an undiagnosed left-to-right shunt before pregnancy, especially atrial septal defect type 2 . To exclude this, we assessed the Qp/Qs ratio, which was within the reference range in all women. Another possibility is pulmonary embolism. Nevertheless, the clinical probability of this disease was low according to the Wells rule (0 points) in all studied women. The echocardiographic examination excluded RV pressure overload in the overall study population. Although pregnancy increases the risk of venous thromboembolism, the prevalence of pulmonary embolism in pregnant women is low (six per 10,000 pregnancies) [16], whereas asymptomatic pulmonary artery dilatation occurred in every third woman in our study. The mean pulmonary artery pressure can be also estimated noninvasively using Mahan's equation, which is based on ACT [16]. However, ACT is correlated with LVCO and heart rate; it increases with increasing LVCO levels and decreases with increasing heart rate. As both LVCO and heart rate increase during pregnancy, the ACT should be interpreted with caution.

Pulmonary artery dilatation may be related to volume overload. In group A, we found a significant increase in RA and left atrial areas, LV dimensions and volume, and in stroke 
volume, as compared with baseline values (Table 4). A higher LV mass indexed to the body surface area and to height (h) ${ }^{2.7}$ in group A in comparison with group B during V2 was probably also secondary to increased volume overload. This observation shows that volume overload and cardiovascular adaptations to these changes may be significantly different in healthy pregnant women.

We also observed a negative association between PAD and SVR, as well as the PI in the uterine artery measured during the second visit. This revealed that PAD is also related to reduced afterload. These changes observed in our study are contrary to those occurring in pre-eclampsia, such as reduced blood volume and increased SVR and PI [17, 18]. Previous studies showed that relaxin, an endothelium-dependent hormone peptide, along with progesterone and oestrogen, prevents an increase in systolic blood pressure, and by stimulating vasopressin secretion and drinking provides increased water retention $[19,20]$. Relaxin acts via nitrate oxygen, and it has been proven that its deficiency may lead to pre-eclampsia $[17,21]$. Although we did not examine the level of relaxin in our study, the volume overload observed in our participants with pulmonary artery dilatation may be partially related to this hormone. This potential association requires further research.

In our study, PAD was also positively correlated with aortic diameter. Other researchers proved that increased aortic distensibility, along with lowered stiffness indices during pregnancy, are caused by intrinsic changes in the arterial wall and are unrelated to afterload [4, 5].

These changes in the aortic wall are probably mediated by oestrogens and include fragmentation of reticular fibres, loss of normal corrugation of elastic fibres, a reduction in acid mucopolysaccharides, and hypertrophy and hyperplasia of smooth muscle cells [22]. This similar mechanism may also be partially responsible for pulmonary artery dilatations during gestation. In a case report by Veil-Picard et al. [23], symptomatic hypoxaemia during pregnancy was described as a result of transient pulmonary arteriovenous dilatation. In this patient, oestrogen-mediated augmentation and proliferation of blood vessels was the probable mechanism, and all symptoms resolved postpartum along with spontaneous regression of vascular changes. Nevertheless, despite a computed tomography scan and numerous echocardiographic examinations, the pulmonary artery dilatation was not described in this case report. Furthermore, none of our patients suffered from dyspnoea.

In contrast to most longitudinal pregnancy studies, instead of three visits, one during each trimester, we scheduled only two visits with an echocardiographic assessment. However, despite this limitation our data allow the observation of morphological and haemodynamic changes throughout gestation. In addition, unlike other studies, we did not enrol a control group or assess parameters other than PAD at the postpartum visit because it was not absolutely necessary for our conclusions.

In summary, this study describes pulmonary artery dilatation in healthy pregnant women without any other abnormal echocardiographic findings and without the signs of shunt or pulmonary embolism. These changes in PAD are associated with volume overload, low vascular resistance, and possibly intrinsic changes in the arterial wall. They coexist with physiological cardiac remodelling during pregnancy, and they usually regress postpartum.

\section{Conflict of interest: none declared}

\section{References}

1. Sanghavi M, Rutherford JD. Cardiovascular physiology of pregnancy. Circulation. 2014; 130(12): 1003-1008, doi: 10.1161/CIRCULATIONAHA.114.009029, indexed in Pubmed: 25223771.

2. Savu O, Jurcuț R, Giuşcă S, et al. Morphological and functional adaptation of the maternal heart during pregnancy. Circ Cardiovasc Imaging. 2012; 5(3): 289-297, doi: 10.1161/CIRCIMAGING.111.970012, indexed in Pubmed: 22455877.

3. Carlin A, Alfirevic Z. Physiological changes of pregnancy and monitoring. Best Pract Res Clin Obstet Gynaecol. 2008; 22(5): 801-823, doi: 10.1016/j.bpobgyn.2008.06.005, indexed in Pubmed: 18760680 .

4. Edouard DA, Pannier BM, London GM, et al. Venous and arterial behavior during normal pregnancy. Am JPhysiol. 1998; 274(5 Pt 2): H1605-H1612, indexed in Pubmed: 9612370.

5. Ulusoy RE, Demiralp E, Kirilmaz A, et al. Aortic elastic properties in young pregnant women. Heart Vessels. 2006; 21(1): 38-41, doi: 10.1007/s00380-005-0872-2, indexed in Pubmed: 16440147.

6. Lang R, Badano L, Mor-Avi V, et al. Recommendations for Cardiac Chamber Quantification by Echocardiography in Adults: An Update from the American Society of Echocardiography and the European Association of Cardiovascular Imaging. Eur Heart J Cardiovasc Imaging. 2015; 16(3): 233-271, doi: 10.1093/ehjci/jev014.

7. Rudski LG, Lai WW, Afilalo J, et al. Guidelines for the echocardiographic assessment of the right heart in adults: a report from the American Society of Echocardiography endorsed by the European Association of Echocardiography, a registered branch of the European Society of Cardiology, and the Canadian Society of Echocardiography. J Am Soc Echocardiogr. 2010; 23(7): 685-713; quiz 786, doi: 10.1016/j.echo.2010.05.010, indexed in Pubmed: 20620859.

8. Bhide A, Acharya G, Bilardo CM, et al. ISUOG practice guidelines: use of Doppler ultrasonography in obstetrics. Ultrasound Obstet Gynecol. 2013; 41(2): 233-239, doi: 10.1002/uog.12371, indexed in Pubmed: 23371348.

9. Tsiaras S, Poppas A. Cardiac disease in pregnancy: value of echocardiography. Curr Cardiol Rep. 2010; 12(3): 250-256, doi: 10.1007/s11886-010-0106-9, indexed in Pubmed: 20424969.

10. Simmons LA, Gillin AG, Jeremy RW. Structural and functional changes in left ventricle during normotensive and preeclamptic pregnancy. Am J Physiol Heart Circ Physiol. 2002; 283(4): H1627-H1633, doi: 10.1152/ajpheart.00966.2001, indexed in Pubmed: 12234817.

11. Katz R, Karliner JS, Resnik R. Effects of a natural volume overload state (pregnancy) on left ventricular performance in normal human subjects. Circulation. 1978; 58(3 Pt 1): 434-441, indexed in Pubmed: 679433.

12. Melchiorre K, Sharma R, Thilaganathan B. Cardiac structure and function in normal pregnancy. Curr Opin Obstet Gynecol. 2012; 24(6): 413-421, doi: 10.1097/GCO.0b013e328359826f, indexed in Pubmed: 23000697. 
13. Chung E, Leinwand LA. Pregnancy as a cardiac stress model. Cardiovasc Res. 2014; 101(4): 561-570, doi: 10.1093/cvr/cvu013, indexed in Pubmed: 24448313.

14. Melchiorre K, Sharma R, Khalil A, et al. Maternal cardiovascular function in normal pregnancy. Hypertension. 2016; 67(4): 754-762, doi: 10.1161/hypertensionaha.115.06667.

15. Ducas RA, Elliott JE, Melnyk SF, et al. Cardiovascular magnetic resonance in pregnancy: insights from the cardiac hemodynamic imaging and remodeling in pregnancy (CHIRP) study. J Cardiovasc Magn Reson. 2014; 16: 1-9, doi: 10.1186/1532-429X-16-1, indexed in Pubmed: 24387349.

16. van de, Badano L, Grapsa J. Right ventricle and pulmonary arterial pressure. In: The EACVI Textbook of Echocardiography. 2017: 171-184.

17. Conrad KP. Pregnancy: Implications for Preeclampsia. 2012 31(1): 15-32.

18. Brennan LJ, Morton JS, Davidge ST. Vascular dysfunction in preeclampsia. Microcirculation. 2014; 21(1): 4-14, doi: 10.1111/micc.12079, indexed in Pubmed: 23890192.
19. Tkachenko O, Shchekochikhin D, Schrier RW. Hormones and hemodynamics in pregnancy. Int J Endocrinol Metab. 2014; 12(2): e14098, doi: 10.5812/ijem.14098, indexed in Pubmed: 24803942

20. Conrad KP, Davison JM. The renal circulation in normal pregnancy and preeclampsia: is there a place for relaxin? Am J Physiol Renal Physiol. 2014; 306(10): F1121-F1135, doi: 10.1152/ajprenal.00042.2014, indexed in Pubmed: 24647709.

21. Fisher C, MacLean M, Morecroft I, et al. Is the pregnancy hormone relaxin also a vasodilator peptide secreted by the heart? Circulation. 2002; 106(3): 292-295, indexed in Pubmed: 12119241.

22. Gongora MC, Wenger NK. Cardiovascular complications of pregnancy. Int J Mol Sci. 2015; 16(10): 23905-23928, doi: 10.3390/ijms161023905, indexed in Pubmed: 26473833.

23. Veil-Picard M, Cattin J, Chopard R, et al. Hypoxaemia during pregnancy: pulmonary arteriovenous dilatation as a likely cause. Eur Respir Rev. 2014; 23(134): 531-533, doi: 10.1183/ /09059180.00003514, indexed in Pubmed: 25445952.

Cite this article as: Golińska-Grzybała K, Wiecheć M, Goliński B, et al. Pulmonary artery dilatation during normal pregnancy. Kardiol Pol. 2018; 76(11): 1542-1550, doi: 10.5603/KP.a2018.0153.

\section{WHAT IS NEW?}

In this paper, we report that the pulmonary artery diameter may increase by 1 to $10 \mathrm{~mm}$ in healthy pregnant women and return to the reference values postpartum. To the best of our knowledge, we are the first to report this observation. These changes in pulmonary artery diameter are associated with volume overload and low vascular resistance. This is of importance because cardiovascular disease remains the main reason for maternal death during pregnancy and postpartum. A profound knowledge of the physiological adaptation of the cardiovascular system to normal pregnancy is essential in order to better distinguish pregnant women who require further examination from those who do not. 